\title{
Mandibular bone mineral density in patients with Behçet's disease
}

\author{
This article was published in the following Dove Press journal: \\ Therapeutics and Clinical Risk Management \\ 14 October 2015 \\ Number of times this article has been viewed
}

\author{
Fatih Asutay' \\ Yusuf Atalay' \\ Ahmet Hüseyin Acar ${ }^{2}$ \\ Hilal Asutay ${ }^{3}$ \\ Selma Eroğlu ${ }^{4}$ \\ Muammer Çağrı Burdurlu \\ 'Department of Oral and Maxillofacial \\ Surgery, Faculty of Dentistry, Afyon \\ Kocatepe University, Afyonkarahisar, \\ ${ }^{2}$ Department of Oral and Maxillofacial \\ Surgery, Faculty of Dentistry, \\ Bezmialem Vakıf University, Istanbul, \\ ${ }^{3}$ Department of Prosthodontics, \\ Faculty of Dentistry, ${ }^{4}$ Department of \\ Physical Therapy and Rehabilitation, \\ Faculty of Medicine, Afyon \\ Kocatepe University, Afyonkarahisar, \\ ${ }^{5}$ Department of Oral and Maxillofacial \\ Surgery, Faculty of Dentistry, Yeditepe \\ University, Istanbul, Turkey
}

Objectives: Behçet's disease (BD) is a chronic, recurring vasculitis of unknown etiology. Patients with BD may use a lot of medications associated with the clinical symptoms. Drugs that are used in the treatment of BD may cause bone loss. The aims of the current study were to compare the bone mineral density (BMD) values between $\mathrm{BD}$ and healthy volunteers and describe the effect of disease duration on mandibular BMD.

Materials and methods: The study comprised 30 healthy volunteers (15 males and 15 females, mean age $35.50 \pm 6.80$ years) and 45 patients with BD ( 24 males and 21 females, mean age $38.93 \pm 8.93$ years $)$. The BD group was subdivided according to disease duration $(0-5,6-10$, and $>10$ years). The BMD value of the mandibular body was determined by the dual energy X-ray absorptiometry technique.

Results: The mean mandibular body BMD values were $1.294 \pm 0.21 \mathrm{~g} / \mathrm{cm}^{2}$ in the control group and $1.216 \pm 0.22 \mathrm{~g} / \mathrm{cm}^{2}$ in the BD patients, although there was no statistically significant difference. The BMD was observed to decrease with increased disease duration but not to a statistically significant degree.

Conclusion: The results of this study showed that although the BMD value decreased as the duration of the disease increased, no statistically significant difference was found between the $\mathrm{BD}$ patients and the healthy control group.

Keywords: Behçet's disease, mandible, bone mineral density, dual energy X-ray absorptiometry

\section{Introduction}

Behçet's disease (BD) is an idiopathic, chronic, relapsing, multisystemic, vasculitic inflammatory disorder presenting with triple-symptom complex of recurrent oral aphthous ulcers, genital ulcers, and uveitis. Gastrointestinal, pulmonary, musculoskeletal, cardiovascular, and neurological systems can be involved. ${ }^{1,2} \mathrm{BD}$ is generally seen in East Asia and the Mediterranean rather than in Western countries. The disease affects both sexes equally and the age of onset is in the third or fourth decade of life. ${ }^{3}$

The etiopathogenesis of BD remains unclear because of its rarity and corresponding lack of clinical evidence, but the most credited hypothesis suggests a complex interaction among immune mechanisms, genetic factors (especially, in Turks and Japanese patients, HLA-B51 gene may be responsible for genetic susceptibility), and environmental factors, such as microbial agents (Saccharomyces cerevisiae, Mycobacteria, Borrelia burgdorferi, Helicobacter pylori, Escherichia coli, Staphylococcus aureus, Mycoplasma fermentans, Streptococcus sanguinis, herpes simplex virus). ${ }^{4-6}$ Chronicity, inflammation, and the drugs used for treatment may lead to bone loss in BD.

Chronic inflammation may cause the development of osteoporosis (OP), which is a significant skeletal disorder characterized by low bone mass. Reduced bone
Correspondence: Fatih Asutay Department of Oral and Maxillofacial Surgery, Faculty of Dentistry, Afyon Kocatepe University, Guvenevler Street Inonu Boulevard No 4, 03030 Afyonkarahisar, Turkey Tel +902722167900 ext 1038 Email dt_asutay@hotmail.com 
mineral density (BMD) and OP are major risk factors for bone fractures and are frequently observed in several rheumatological disorders such as BD, rheumatoid arthritis (RA), ankylosing spondylitis, familial Mediterranean fever (FMF), and systemic lupus erythematosus (SLE). ${ }^{7-9}$ Besides the chronic inflammation, the drugs used for treatment of the various symptoms of BD such as anticonvulsants, corticosteroids, disease-modifying antirheumatic drugs, hormone replacement therapy, bisphosphonates, vitamin D, xuoride, calcitonin, and diuretics may affect bone mineral status. ${ }^{10,11}$ Some studies have suggested that long-term drug use may reduce $\mathrm{BMD},{ }^{12,13}$ although evidence of the real effect remains controversial. $^{10}$

BMD is seen as an important factor in treatment planning by oral surgeons and affects the success of dentomaxillofacial operations such as bone grafting, periodontal procedures, and especially dental implants. ${ }^{14-17}$ In the success of dental implant surgery, osteointegration is influenced by bone volume and quality. ${ }^{18}$ Therefore, systemic inflammatory diseases that affect BMD become a highly significant and attractive issue for oral surgeons.

In the evaluation of BMD, dual energy X-ray absorptiometry (DXA) is a valid, noninvasive technique. Some studies have reported investigations of lumbar and femoral BMD in patients with BD. ${ }^{3,10}$ However, to the best of our knowledge, the effect of BD on mandibular bone density has not yet been investigated. The first aim of the present study was to evaluate mandibular BMD in BD patients with DXA. The second aim was to compare the BMD values of BD patients and healthy subjects using DXA. The third aim was to describe the effect of long-term disease duration on BMD.

\section{Materials and methods}

\section{Patients}

Approval for the study was granted by the Ethics Committee of Bezmialem Vakif University Faculty of Medicine. DXA examinations were then applied in the Bone Densitometry Unit of the Department of Physical Medicine and Rehabilitation of Afyon Kocatepe University.

The study included 45 adults with BD (male/female: 24/21) and 30 volunteer healthy adults (male/female: 15/15) as a control group. All patients gave informed written consent. A questionnaire was used to collect information on age, sex, disease history, drug status, menopausal status, weight, and height. The control group was randomly chosen from patients in the Department of Oral and Maxillofacial Surgery, Faculty of Dentistry, Afyon Kocatepe University. All BD patients were receiving $1-1.5 \mathrm{mg} /$ day of colchicines therapy.
The patients were divided into four groups according to the disease duration: healthy controls (group 1); patients with BD between 0 and 5 years disease duration (group 2); patients with BD between 6 and 10 years disease duration (group 3); and patients with BD more than 10 years disease duration (group 4).

\section{Exclusion criteria}

Patients who had been previously diagnosed with any systemic disease other than BD or who had taken any drugs in the last 6 months which could affect BMD (including steroids, anticonvulsants, corticosteroids, disease-modifying antirheumatic drugs, hormone replacement therapy, bisphosphonates, vitamin D, xuoride, calcitonin, and diuretics) were excluded from the study.

Patients with considerable infection or bone pathology (cysts and tumours), absence of all premolars and molars in the lower jaw, and edentulous patients were also excluded.

\section{BMD measurement}

Scans of the mandible were performed and BMD $\left(\mathrm{g} / \mathrm{cm}^{2}\right)$ was calculated using the DXA device (GE Lunar DPX-NT, LUNAR Corp., Madison, WI, USA). Scanning procedures and BMD measurements were performed on the body of the mandible as previously described (Figure 1). ${ }^{19-21}$ The BMD of the mandible was measured and analyzed by a singleblind operator.

\section{Statistical analysis}

Statistical analysis was performed with the Statistical Package for the Social Science Program (version 20.0, IBM Corporation, Armonk, NY, USA). The normality and homogeneity

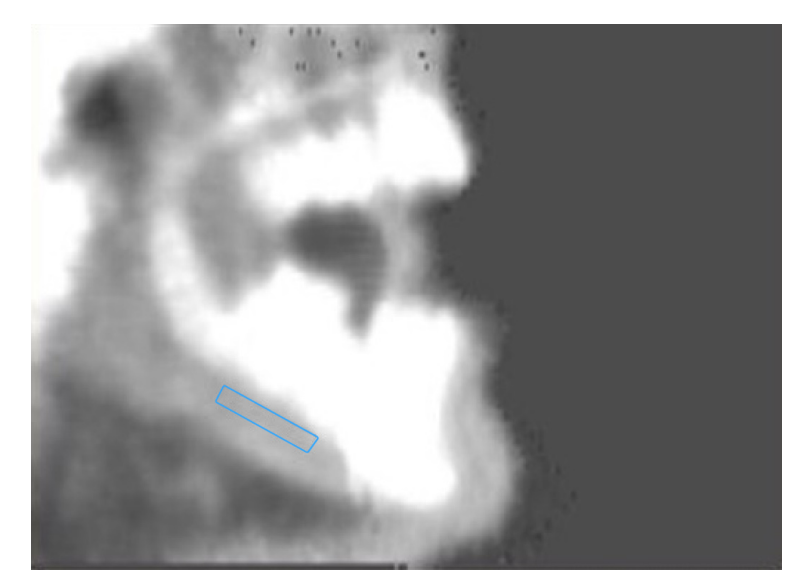

Figure I Measurement of mandibular BMD by dual-energy X-ray absorptiometry. Abbreviation: BMD, bone mineral density. 
of the sample were confirmed by the Shapiro-Wilk tests, after which the one-way analysis of variance/Tukey honest significant difference tests were used to determine any intergroup differences. Differences in individual parameters between the whole $\mathrm{BD}$ group and the control group were tested using the Student's $t$-test. A value of $P<0.05$ was considered statistically significant.

\section{Results}

Evaluation was made of the data of 75 patients, comprising 36 females (48\%) and 39 males (52\%), with a mean age of 37.56 \pm 8.2 years (range: 22-63 years) (Tables 1 and 2). There was only a significant difference between group 4 and the other groups regarding age $(P<0.05)(47.27 \pm 7.5$ years [range: 34-63 years]) (Table 1).

The characteristics of the study participants are shown (mean $\pm \mathrm{SD}$ ) in Tables 1 and 2. There was no statistically significant difference between the study and control groups with respect to sex and body mass index (BMI) variables $(P>0.05)$.

There was found to be no statistically significant difference between the three study groups and the control group in respect of the mandibular body BMD $(P>0.05)$. However, the mandibular body BMD was highest in the control group patients $\left(1.294 \pm 0.21 \mathrm{~g} / \mathrm{cm}^{2}\right)$ and gradually reduced through the study subgroups (group 2: $1.251 \pm 0.22 \mathrm{~g} / \mathrm{cm}^{2}$, group 3: $1.249 \pm 0.20 \mathrm{~g} / \mathrm{cm}^{2}$, group 4: $1.147 \pm 0.24 \mathrm{~g} / \mathrm{cm}^{2}$ ) (Table 1). No statistically significant differences were determined $(P>0.05)$ (Table 2).

\section{Discussion}

This study with a relatively small sample size group examined the comparison of mandibular BMD between BD patients and healthy individuals and showed that although there was no statistically significant difference, bone loss can occur in BD patients. To the best of our knowledge, this is the first study in the literature to investigate mandibular body $\mathrm{BMD}$ in $\mathrm{BD}$ patients.
The findings of the study showed the mean mandibular body BMD value of $1.294 \pm 0.21 \mathrm{~g} / \mathrm{cm}^{2}$ in the control group and $1.247 \pm 0.22 \mathrm{~g} / \mathrm{cm}^{2}$ in all the participants in our study which is similar to the findings of Buyukkaplan et $\mathrm{al}^{20}$ $\left(1.10 \pm 0.31 \mathrm{~g} / \mathrm{cm}^{2}\right)$, Pluskiewicz et $\mathrm{al}^{22}\left(1.221 \pm 0.3 \mathrm{~g} / \mathrm{cm}^{2}\right)$, Devlin and Horner $^{23}\left(1.15 \pm 0.26 \mathrm{~g} / \mathrm{cm}^{2}\right)$, Drage et $\mathrm{al}^{24}(1.38 \pm 0.39$ $\left.\mathrm{g} / \mathrm{cm}^{2}\right)$, and Esfahanizadeh et $\mathrm{al}^{21}\left(1.386 \pm 0.320 \mathrm{~g} / \mathrm{cm}^{2}\right)$. Different BMD values in studies may be associated with "region of interest (ROI)" or dentulous/edentulous patients.

OP is a systemic skeletal disorder characterized by bone loss and structural deterioration of bone tissue, which may lead to bone fragility and an increased susceptibility to fractures. Recently, there have been many studies on OP in several rheumatological and chronic inflammatory disorders such as BD, RA, ankylosing spondylitis, FMF, and SLE. ${ }^{7-9}$ In these diseases, multiple factors may be responsible for bone mass reduction, especially the inflammatory process and the treatment drugs.

$\mathrm{BD}$ is a polysymptomatic and recurrent systemic vasculitis with a chronic course and unknown cause. In the inflammatory process, proinflammatory cytokines, such as tumor necrosis factor- $\alpha$, interleukin- (IL-) $1 \beta$, IL-6, and IL-17 can upregulate and may cause increased bone resorption and decreased BMD. ${ }^{3,25}$ According to the degree of the disease, various drugs are used to control the signs and symptoms of $\mathrm{BD}$. The main goal of drug therapy is to reduce symptoms, reduce inflammation, control the immune system, maintain remission, and improve the patient's quality of life. Although there has been no consensus on a treatment program, many medications have been used to reduce inflammation or modify the immune system, including colchicine, corticosteroids, antitumor necrosis factor agents (infliximab and etanercept), thalidomide, and cyclosporine. ${ }^{1}$ Colchicine and corticosteroids are suspected to reduce BMD.

Due to the inflammatory processes and long-term drug use, BMD may be affected by the disease duration and activity. Laan et $\mathrm{al}^{12}$ reported that BMD can be reduced with a long-term disease duration in patients with RA. However,

Table I Characteristics of patients (all groups) according to age, BMI, and BMD

\begin{tabular}{llll}
\hline Characteristics & Age & BMI $\left(\mathbf{k g} / \mathbf{m}^{2}\right)$ & BMD $\left(\mathbf{g} / \mathbf{c m}^{2}\right)$ \\
\hline Group I (controls) & $35.5 \pm 6.8(22-45)$ & $28.20 \pm 4.7(19.3-37.5)$ & $1.294 \pm 0.21(0.86-1.7 I)$ \\
Group 2 (0-5 years) & $33.67 \pm 6.5(23-44)$ & $27.49 \pm 5.7(17.1-39.3)$ & $1.25 I \pm 0.22(0.83-1.55)$ \\
Group 3 (5-10 years) & $35.87 \pm 6.0(27-45)$ & $24.90 \pm 3.5(19.4-32.5)$ & $1.249 \pm 0.20(0.83-1.52)$ \\
Group 4 (+10 years) & $47.27 \pm 7.5(34-63)$ & $26.85 \pm 4.2(21.1-34.4)$ & $1.147 \pm 0.24(0.79-1.57)$ \\
Total & $37.56 \pm 8.2(22-63)$ & $27.12 \pm 4.7(17.1-39.3)$ & $1.247 \pm 0.22(0.79-1.71)$ \\
P-values* & 0.000 & 0.167 & 0.228 \\
\hline
\end{tabular}

Notes: *One-way ANOVA test, Tukey HSD. Data are represented as mean \pm standard deviation.

Abbreviations: ANOVA, analysis of variance; BMD, bone mineral density; BMI, body mass index; HSD, honest significant difference. 
Table 2 Characteristics of patients (all Behçet's patients and controls) according to age, BMI, and BMD

\begin{tabular}{llll}
\hline Characteristics & Age & BMI $\left(\mathbf{k g} / \mathbf{m}^{2}\right)$ & BMD $\left(\mathbf{g} / \mathbf{c m}^{2}\right)$ \\
\hline All Behçet's patients & $38.93 \pm 8.93$ & $26.4 \pm 4.6$ & $1.216 \pm 0.22$ \\
Controls & $35.50 \pm 6.80$ & $28.2 \pm 4.7$ & $1.294 \pm 0.21$ \\
Total & $37.56 \pm 8.2$ & $27.12 \pm 4.7$ & $1.247 \pm 0.22$ \\
$P$-value* & 0.078 & 0.108 & 0.139 \\
\hline
\end{tabular}

Note: *Student's t-test.

Abbreviations: BMD, bone mineral density; BMI, body mass index.

Biçer et $\mathrm{al}^{10}$ reported no association between disease duration and BMD. In the present study, a reduction in BMD values was determined in patients with long-term disease duration, although it was not statistically significant.

In oral and maxillofacial surgery, decreased BMD can affect the decision-making for placement, success/survival and osseointegration of dental implants, success of bone regeneration therapies (osteotomies, bone augmentations, guided-bone-regeneration, and bone grafting), and bone loss in periodontitis. ${ }^{26-29}$ Studies have shown a positive correlation between BMD and bone quality. ${ }^{30-32}$ Pommer et $\mathrm{al}^{33}$ found that radiographic bone density significantly impacted implant stability values and local jawbone density was reported to be the major determinant of primary implant stability in the maxillary sinus floor of shortened height. Türkyılmaz et al ${ }^{34}$ reported significant correlations between bone quality and implant stability parameters. Therefore, all diseases and conditions that affect BMD are closely related to oral surgery.

Esfahanizadeh et $\mathrm{al}^{21}$ reported that since there was a significant correlation between the densities of skeletal and jaw bones and the presence of OP or osteopenia, the maxilla and mandible may reflect the same situation. Pluskiewicz et $\mathrm{al}^{22}$ also reported that mandibular BMD may be an appropriate measurement site for assessment of OP. However, Gulsahi et $\mathrm{al}^{35}$ suggested that the BMD of the jaws was not correlated with femoral BMD. It was explained that these different results may have arisen from different sizes of ROI selection and the measurement of specific areas (anterior, premolar and molar regions of maxilla and mandible).

Mandibular BMD can be measured in the body, symphysis, and ramus regions. Horner et $\mathrm{al}^{36}$ suggested that the mandibular body has greater sensitivity and specificity compared with the ramus and symphysis regions in the detection of OP. Therefore, in the present study, the BMD measurements were performed on the body of the mandible.

DXA is the gold standard for measurement of BMD. Due to its rapid, highly reproducible, very precise, low cost, and radiation dosage properties, DXA is the most widely accepted and utilized technology. ${ }^{37}$

\section{Limitations}

Limitations of the present study include the small sample size and that there was no information about drug dosages and types and dentolous/edentulous patients. Further studies are needed of larger study groups.

\section{Conclusion}

The results of this study have shown that long-term disease duration may cause decreased mandibular BMD and BD patients had lower BMD than control group, although it was not statistically important.

\section{Disclosure}

The authors report no conflicts of interest in this work.

\section{References}

1. Saleh Z, Arayssi T. Update on the therapy of Behcet disease. Ther Adv Chronic Dis. 2014;5(3):112-134.

2. Rigante $D$. The fresco of autoinflammatory diseases from the pediatric perspective. Autoimmun Rev. 2012;11(5):348-356.

3. Tekin NS, Ozdolap S, Sarikaya S, Esturk E, Gumustas S. Bone mineral density and bone turnover markers of patients with Behcet's disease. J Eur Acad Dermatol Venereol. 2007;21(1):25-29.

4. Yurdakul S, Yazici H, Tuzun Y, et al. The arthritis of Behcet's disease: a prospective study. Ann Rheum Dis. 1983;42(5):505-515.

5. Direskeneli H. Behcet's disease: infectious aetiology, new autoantigens, and HLA-B51. Ann Rheum Dis. 2001;60(11):996-1002.

6. Galeone M, Colucci R, D'Erme AM, Moretti S, Lotti T. Potential infectious etiology of Behcet's disease. Patholog Res Int. 2012;2012:595380.

7. Martin JC, Munro R, Campbell MK, Reid DM. Effects of disease and corticosteroids on appendicular bone mass in postmenopausal women with rheumatoid arthritis: comparison with axial measurements. Br J Rheumatol. 1997;36(1):43-49.

8. Juanola X, Mateo L, Nolla JM, Roig-Vilaseca D, Campoy E, RoigEscofet D. Bone mineral density in women with ankylosing spondylitis. J Rheumatol. 2000;27(4):1028-1031.

9. Gilboe IM, Kvien TK, Haugeberg G, Husby G. Bone mineral density in systemic lupus erythematosus: comparison with rheumatoid arthritis and healthy controls. Ann Rheum Dis. 2000;59(2):110-115.

10. Bicer A, Tursen U, Kaya TI, et al. Bone mineral density in patients with Behcet's disease. Rheumatol Int. 2004;24(6):355-358.

11. Skef W, Hamilton MJ, Arayssi T. Gastrointestinal Behcet's disease: a review. World J Gastroenterol. 2015;21(13):3801-3812.

12. Laan RF, Buijs WC, Verbeek AL, et al. Bone mineral density in patients with recent onset rheumatoid arthritis: influence of disease activity and functional capacity. Ann Rheum Dis. 1993;52(1):21-26.

13. Gough AK, Lilley J, Eyre S, Holder RL, Emery P. Generalised bone loss in patients with early rheumatoid arthritis. Lancet. 1994;344(8914): $23-27$.

14. Jemt $\mathrm{T}$, Lekholm U. Implant treatment in edentulous maxillae: a 5-year follow-up report on patients with different degrees of jaw resorption. Int J Oral Maxillofac Implants. 1995;10(3):303-311.

15. Jaffin RA, Berman CL. The excessive loss of Branemark fixtures in type IV bone: a 5-year analysis. J Periodontol. 1991;62(1):2-4.

16. Klemetti E, Collin HL, Forss H, Markkanen H, Lassila V. Mineral status of skeleton and advanced periodontal disease. J Clin Periodontol. 1994; 21(3):184-188.

17. Tezal M, Wactawski-Wende J, Grossi SG, Ho AW, Dunford R, Genco RJ. The relationship between bone mineral density and periodontitis in postmenopausal women. J Periodontol. 2000;71(9):1492-1498. 
18. van Steenberghe D, Quirynen M, Molly L, Jacobs R. Impact of systemic diseases and medication on osseointegration. Periodontol 2000 2003;33:163-171.

19. Buyukkaplan US, Guldag MU, Yildiz M, Gumus BA. Comparison of mandibular bone mineral density in osteoporotic, osteopenic and normal elderly edentulous subjects measured by the dual-energy X-ray absorptiometry technique. Gerodontology. 2012;29(2):e1098-e1102.

20. Buyukkaplan US, Tonguc MO, Guldag MU, Yildiz M, Gumus BA. Comparison of mandibular bone mineral densities in dentate and edentulous patients. J Prosthodont. 2013;22(1):23-27.

21. Esfahanizadeh N, Davaie S, Rokn AR, et al. Correlation between bone mineral density of jaws and skeletal sites in an Iranian population using dual X-ray energy absorptiometry. Dent Res J (Isfahan). 2013;10(4):460-466.

22. Pluskiewicz W, Tarnawska B, Drozdzowska B. Mandibular bone mineral density measured using dual-energy X-ray absorptiometry: relationship to hip bone mineral density and quantitative ultrasound a calcaneus and hand phalanges. Br J Radiol. 2000;73(867):288-292.

23. Devlin H, Horner K. A study to assess the relative influence of age and edentulousness upon mandibular bone mineral density in female subjects. Oral Surg Oral Med Oral Pathol Oral Radiol Endod. 2007; 104(1):117-121.

24. Drage NA, Palmer RM, Blake G, Wilson R, Crane F, Fogelman I. A comparison of bone mineral density in the spine, hip and jaws of edentulous subjects. Clin Oral Implants Res. 2007;18(4):496-500.

25. Lane NE, Rehman Q. Osteoporosis in the rheumatic disease patient. Lupus. 2002;11(10):675-679.

26. Blomqvist JE, Alberius P, Isaksson S, Linde A, Hansson BG. Factors in implant integration failure after bone grafting: an osteometric and endocrinologic matched analysis. Int J Oral Maxillofac Surg. 1996; 25(1):63-68.

27. August M, Chung K, Chang Y, Glowacki J. Influence of estrogen status on endosseous implant osseointegration. J Oral Maxillofac Surg. 2001;59(11):1285-1289; discussion 1290-1281.
28. Gondim V, Aun J, Fukuda CT, et al. Severe loss of clinical attachment level: an independent association with low hip bone mineral density in postmenopausal females. J Periodontol. 2013;84(3):352-359.

29. Passos JS, Vianna MI, Gomes-Filho IS, et al. Osteoporosis/osteopenia as an independent factor associated with periodontitis in postmenopausal women: a case-control study. Osteoporos Int. 2013;24(4):1275-1283.

30. Fuster-Torres MA, Penarrocha-Diago M, Penarrocha-Oltra D, Penarrocha-Diago M. Relationships between bone density values from cone beam computed tomography, maximum insertion torque, and resonance frequency analysis at implant placement: a pilot study. Int $J$ Oral Maxillofac Implants. 2011;26(5):1051-1056.

31. Kido H, Schulz EE, Kakura K, Yamamoto K, Morinaga K, Matsuura M. Human mandibular trabecular bone density correlation with mechanical strength: implications for implant dentistry. Implant Dent 2011;20(4):323-326.

32. Munakata M, Tachikawa N, Honda E, Shiota M, Kasugai S. Influence of menopause on mandibular bone quantity and quality in Japanese women receiving dental implants. Arch Osteoporos. 2011;6:51-57.

33. Pommer B, Hof M, Fadler A, Gahleitner A, Watzek G, Watzak G. Primary implant stability in the atrophic sinus floor of human cadaver maxillae: impact of residual ridge height, bone density, and implant diameter. Clin Oral Implants Res. 2014;25(2):e109-e113.

34. Turkyilmaz I, McGlumphy EA. Influence of bone density on implant stability parameters and implant success: a retrospective clinical study. BMC Oral Health. 2008;8:32.

35. Gulsahi A, Paksoy CS, Ozden S, Kucuk NO, Cebeci AR, Genc Y. Assessment of bone mineral density in the jaws and its relationship to radiomorphometric indices. Dentomaxillofac Radiol. 2010;39(5):284-289.

36. Horner K, Devlin H, Alsop CW, Hodgkinson IM, Adams JE. Mandibular bone mineral density as a predictor of skeletal osteoporosis. Br J Radiol. 1996;69(827):1019-1025.

37. Maricic M. Use of DXA-based technology for detection and assessment of risk of vertebral fracture in rheumatology practice. Curr Rheumatol Rep. 2014;16(8):436.
Therapeutics and Clinical Risk Management

\section{Publish your work in this journal}

Therapeutics and Clinical Risk Management is an international, peerreviewed journal of clinical therapeutics and risk management, focusing on concise rapid reporting of clinical studies in all therapeutic areas outcomes, safety, and programs for the effective, safe, and sustained use of medicines. This journal is indexed on PubMed Central, CAS,

\section{Dovepress}

EMBase, Scopus and the Elsevier Bibliographic databases. The manuscript management system is completely online and includes a very quick and fair peer-review system, which is all easy to use. Visit http://www.dovepress.com/testimonials.php to read real quotes from published authors. 